Удк 328.26(477)

\title{
БЕЙЛИНЙОСИ,
}

Ph.D., директор организачии Beilink, Business Foreign Affairs, экс-министр юстиции Израиля

\section{КРАВЧУК ЛИАТ,}

директор организаџии Jeneba Project, Inc., Израиль

\section{ПОСТРОЕНИЕ ДОРОЖНОЙ КАРТЫ ДЛЯ РАЗРЕШЕНИЯ КОНФЛИКТА И ПРОВЕДЕНИЯ ПРЕОБРАЗОВАНИЙ В УКРАИНЕ}

В статье обосновывается подход к трансформации украинского конфликта, в рамках которого нынешний кризис признается как проявление глубинных напряженностей. Предлагается двухаспектный подход к достижению мира в регионе: а) путем осуществления многосторонней дипломатии, ориентированной на изменение аспектов поведения и установок участников конфликта; б) путем создания органа восстановительного правосудия по типу южноафриканского комитета правды и примирения. Предлагаемые автором стратегические шаги, направленные на мирное завершение конфликта, таковы: а) проведение реформ по децентрализации Украины; б) решение вопроса Крыма путем всенародного референдума; в) обозначение экономической безопасности как приоритетного пути для достижения политической безопасности; г) постепенное создание стратегических альянсов, которые предусмотрят членство Украины в ЕС, но не в НАТО, в ближайшие годы.

Ключевые слова: Украина; Крым; конфрликт; дорожная карта; стратегия.

Недавно в Донецке вновь вспыхнуло насилие, положившее конец хрупкому перемирию, достигнутому 5 сентября 2014 года в Минске. Это ознаменовало возобновление конфликта, который стал самым неразрешимым противоречием между Западом и Россией со времен холодной войны и самым кровавым конфликтом в Европе со времен Балканских войн, в котором погибло более 5,000, ранено 10,000 и стали беженцами миллион человек [1].

Конфликт этот многогранен, тесно переплетен и должен решаться на разных уровнях. С одной стороны, перед нами украинская гражданская война между сторонниками послереволюционной власти Западной Украины и восточными украинцами, среди которых многие поддерживают Россию, и сепаратистами [2]. С другой стороны, внутренняя напряженность эксплуатировалась и обострялась для того, чтобы подпитать опосредованную войну между Западом и Россией, сущностно выраженную аннексией Крыма, которая служила в качестве символа и продолжения исторического раскола Востока и Запада.

Военные решения нереалистичны и могут быть контрпродуктивными. Поставки оружия президенту Порошенко как прямой вызов российским силам или размещение постоянных баз НАТО в добавок к странам Балтии, вероятно, приведет к эскалации военного кризиса и резкому увеличению числа пострадавших среди мирного населения [3]. Аналогичным образом, непродуктивно давление на президента Путина путем введения более жестких санкций, так как он по-прежнему пользуется подавляющей поддержкой в своей стране.

Политическое решение, таким образом, это самый прагматичный подход. В данной статье предлагается двухаспектный подход кдостижению мира в регионе.
Сначала обозначается подход трансформации конфликта, в рамках которого мы признаем нынешний кризис как проявление глубинных напряженностей, и который направлен на изменение аспектов поведения и установок участников конфлликта путем: а) осуществления многосторонней дипломатии, ориентированной на Второе направление; и б) создания органа восстановительного правосудия, такой же модели как южноафриканский комитет правды и примирения.

Затем будут предложены методы разрешения конфрликта, направленные на содействие мирному завершению текущего конфликта с помощью стратегических шагов. Они таковы: а) проведение реформ по децентрализации Украины; б) решение вопроса Крыма путем всенародного референдума; в) обозначение экономической безопасности как приоритетного пути для достижения политической безопасности; и г) постепенное создание стратегических альянсов, которые предусмотрят членство Украины в ЕС, но не в НАTO, в ближайшие годы.

\section{Оппозиционные трактовки}

Украина - страна со сложной историей и многоязычным многонациональным населением. Получив независимость лишь в 1991 году, после более чем 500 лет внешнего правления, страна не успела еще выковать сильное национальное самосознание, национальную идею.

Страна часто описывается как разделенная на два конфликтующих региона, и каждая попытка одной группы доминировать над другой выводит страну на грань гражданской войны [4]. С одной стороны - Западная Украина, которая была включена в состав СССР в 1939 году и состоит в основном из католиков с проза- 
падными тенденциями. С другой - Восточная (и Южная) Украина, где проживает в основном православное, преимущественно русскоговорящее население с пророссийскими настроениями (и на краю этого региона - Крым, ставший частью Украины лишь в 1954 году). На самом деле, хотя история каждого из регионов придает им характерные отличительные свойства, разделение не столь четкое, и любые попытки оторвать восточную Украину от страны вероятнее всего будут встречены сопротивлением не только со стороны Западной Украины, но и широких масс украинцев, живущих на востоке, включая русскоязычных, которые выразили лояльность Украине.

Глубокие, фундаментальные противоречия уже давно создавали напряженность между сторонами; прозападные сторонники воспринимают Москву как исторического узурпатора независимости Украины, а провосточно настроенные воспринимают сторонников Киева как предателей, которые сотрудничали с Гитлером и представляют угрозу для общих русских корней двух наций [5].

В последние годы конфликт был сопряжен с информационными войнами относительно того, как начался кризис в Украине. С одной стороны, российское изложение истории предполагает, что массовые акции протеста против украинского президента Виктора Януковича и его изгнание, под маской которого скрывались расширение НАТО или инициативы Европейского Союза, были не только поддержаны, но организованы на Западе, чтобы установить прозападные режимы и консолидировать зоны влияния у российских границ [6].

Западная версия истории предполагает, что массовые демонстрации против президента Виктора Януковича в 2004-2005 и его свержение в 2014 году были оправданной реакцией на его псевдо-демократический режим кумовства и коррупции и решение о заключении формального договора с Евразийским экономическим союзом Путина против воли украинского народа вместо вступления в Европейский Союз.

Во-вторых, относительно соглашения от 21 февраля, в котором Янукович согласился на сделку о разделе власти при посредничестве EC, а затем бежал в Россию, сторонники Москвы считают, что оппозиция устроила антиконституционный переворот и военный захват власти. Исходя из этого, они отрицают легитимность нынешней украинской власти и отказываются признать ее в качестве партнера по переговорам.

Запад подчеркивает, что Янукович не исполнил свою часть сделки, сбежав и оставив позади свидетельства о широкомасштабной коррупции [7] и таким образом, потерял всю поддержку внутри страны [5]. Это касается российских шагов по Крыму как попытки создать и сохранить влияние на политические процессы в Украине, учитывая, что у Кремля нет отношений с новыми политическими субъектами в Киеве, и таким образом он использует военную силу, чтобы утвердить гегемонию в регионе [6].

В-третьих, Москва видит Киев, как оказавшийся во власти украинских националистов и экстремистов, которые угрожают безопасности русского меньшинства. Это мнение вызвано попыткой нового правительства аннулировать закон о языке, принятый Януковичем в 2012 году, повышающий статус русского языка. Согласно военной доктрине 2010 года, российские вооруженные силы могут быть развернуты, если безопасность российских граждан за пределами своих границ находится под угрозой. Для оправдания аннексии Крыма,
Кремль сослался на просьбы о помощи от Януковича, которого он считает легитимным президентом Украины, и представил это как попытку стабилизации ситуации в Украине [там же]. Кроме того, Путин утверждает, что защищает другие уязвимые меньшинства и заявляет о массовых нападениях на церкви и синагоги в южной и восточной части Украины.

Запад утверждает, что нет достоверных сообщений об угрозе этническим русским и что исполнявший на тот момент обязанности президента Турчинов отказался подписать законодательство, ограничивающее использование русского языка на региональном уровне [7]. Они подчеркивают, что не было никаких нападений на церкви и что еврейские организации в южной и восточной части Украины не видят учащения антисемитских инцидентов [там же]. Запад считает, что Путин использует любой повод, чтобы попытаться воссоздать Советский Союз. Они также рассматривают его действия как политическую функцию, направленную на подчинение оппозиции в России и восстановление легитимности во имя защиты сферы влияния России [6].

\section{I. Необходимые шаги для трансформации конф-} ликта

В этом разделе описываются меры, которые могут трансформировать конфликтные отношения, лежащие в основе нынешнего конорликта в Украине и поддерживающие его продолжение на уровнях интересов, дискурса, межгрупповом и социально-структурном уровнях [8].

а. Многосторонняя дипломатия с упором на второе направление

В первую очередь, необходимо разобраться в противоречивых представлениях об Украине по таким вопросам как история, личная и коллективная безопасность, ценности, экономические выгоды, язык и т.д., пока конфликт не стал неразрешимым, не стал неотъемлемой частью повседневной жизни и доминирующей силой в формировании антагонистичных идентичностей. Пока все стороны (Украина, Россия, и страны Запада) продолжают приравнивать к победе управление общественным дискурсом [9], воинственность будет расти как среди международных лидеров, так и среди украинцев.

Для того чтобы перейти к деэскалации и стабилизации, должны быть предприняты некоторые шаги. Вопервых, такие организации, как ОБСЕ, должны продолжать играть роль нейтральных локально расположенных наблюдателей, чтобы факты, а не слухи, были основой для принятия политических решений [10].

Во-вторых, переговоры на высшем уровне должны проходить под эгидой международных миротворческих организаций с участием всех сторон, в том числе украинских фракций, ЕС, США и России. Третьи стороны, такие как Миссия специального мониторинга ОБСЕ в Украине [11] могли бы способствовать принятию соглашений, а Совет Европы мог бы служить форумом для диалога между сторонами [12]. Все договаривающиеся стороны должны включать в себя мужчин, женщин и представителей меньшинств.

Одновременно с этим должна проводиться неформальная дипломатия (дипломатия запасного пути), включающая интенсивный устойчивый неформальный диалог для противоборствующих сторон, как важный шаг не только для разрядки напряженности, но и как основное средство конструктивных изменений. Цель таких переговоров для сторон состоит в том, чтобы критически оценить свои собственные интерпретации [6] 
и взять на себя ответственность за глубоко укоренившуюся трагедию, которая разворачивается сейчас [12] без страха потерять лицо. Для успешности диалога необходимо, чтобы он включал следующие действия и принципы:

- каждая сторона должна очертить свои основные цели и запросы. Часто группы имеют общее представление о целях, к достижению которых они стремятся, но как только они садятся за стол переговоров, становится ясно, что им еще нужно разобраться во многих деталях и резервных вариантах;

- каждая сторона должна представить претензии других групп как она их понимает. Это может прояснить недопонимания и определить ожидания;

- стороны должны принять дискурс, который фокусируется на потребностях, а не на правах. Например, вместо того чтобы настаивать на сельскохозяйственных полях из-за исторических претензий, более прагматичной может быть просьба современного жилья; вместо того, чтобы заявлять свои права на водоем, стороны могут определить необходимое количество воды, и т.д.;

- необходимо избегать давления на стороны для получения обещаний, которые они вряд ли смогут сдержать. Часто в переговорах сильная сторона давит на слабую, заставляя ее давать нереалистичные обещания. Нарушенные обещания часто становятся поводом разорвать переговоры на более поздних стадиях;

- вместо того, чтобы делить ресурсы, которые важны для обеих сторон, нужно создать площадку для совместного использования;

- необходимо включить женщин, а также представителей уязвимых меньшинств, для которых высоки ставки на переговорах, чтобы их голоса непременно были услышаны. Помимо русскоязычных украинцев, это могут быть члены еврейских или ЛГБТ-сообществ, которые ощущают угрозу со стороны военизированных групп, таких как батальон "Азов", который использует, так пишет [3], нацистские знаки, а также крымских татар, которые столкнулись с расизмом и исламофобией из России [13];

- включить экстремистские группы, которые в противном случае могут выступать в качестве нарушителей мира, такие как пророссийские сепаратисты и члены ультра-националистических групп вроде Правого Сектора.

б. Реализация восстановительного правосудия через Комитет истины и примирения (КИП)

Помимо дипломатии "запасного пути" нужно рассмотреть вариант применения многоязычного Комитета истины и примирения (по образцу такого комитета в Южной Афррике). Одной из целей этой инициативы будет создание Комитета по нарушениям прав человека, с целью проведения общественных слушаний, в которых жертвы конфликта могут рассказать о своем опыте, а виновные смогут явиться в обмен на какую-либо форму амнистии (точные параметры нужно будет определить). Формирование климата открытости, дающего возможность критического анализа истории взаимоотношений групп (восточных и западных украинцев, меньшинств, таких как татары, евреи и т.д.), послужит необходимой основой для восстановления, реабилитации человеческого и гражданского достоинства и примирения. Такая платформа может придавать равновесие всем противоположным интерпретациям, которые часто основаны на дезинформации. Похожий комитет можно учредить для озвучивания жалоб против коррупции.
Украинский КИП в дальнейшем может послужить основой для нового, коллективного национального самосознания, которое так и не было полностью сформировано из-за относительно юной независимости страны и ее сложной истории. Объединение людей с разными социальными идентичностями, разной верой и истиной, для того, чтобы поделиться взглядами на ситуацию, подтверждая при этом значимость индивидуального опыта каждого человека, а не концентрируясь на злодействах другой группы, может способствовать формированию коллективной правды. Кроме того, такой фрорум мог бы уменьшить стереотипизированность образов и восприятия поведения таких групп, например, приравнивание языка к региональной лояльности. После такого символического достойного перехода граждан к равноправию и уважению, люди смогут почувствовать себя включенными в одно государство. Кроме того, сам характер примирения может стать примером и, таким образом, обеспечить доверие политическим процессам демократизации и справедливости.

\section{II. Шаги по разрешению конфоликта}

Данный раздел посвящен шагам, которые должны быть предприняты для стратегического управления и сдерживания текущего конфликта и продвижения противоборствующих сторон к положительным результатам.

\section{а. Децентрализационная реформа}

Споры по поводу того, нужно ли Украине стать децентрализованной, ведутся давно; пик их пришелся на начало 1990-х годов, когда Крым хотел отделиться, и на время Оранжевой революции, когда восточные и южные регионы угрожали сформировать свою собственную республику [14].

Для того, чтобы разрешить текущий кризис и установить основы для долгосрочного мира и развития в Украине, страна должна пройти конституционную реформу в направлении децентрализации. В настоящее время правительство слабо мотивировано на создание бюрократических институтов и несет мало обязательств по реагированию на потребности граждан, так как Конституция Украины дает президенту полномочия назначать и увольнять местных губернаторов, что крайне необычно для парламентских демократий. Централизованный контроль над местными органами власти обострил региональную напряженность и затруднил веру в демократическое руководство [15] как не-встроенную политическую структуру, где местные власти номинально подотчетны своему народу, тогда как на самом деле они подотчетны внешним централизованным силам, что привело к возникновению чувства маргинализации.

Предоставление более широких полномочий региональной власти укрепит демократический характер Украины и позволит представить интересы меньшинств, чья невозможность выразить недовольство в демократическом процессе может стать стимулом, чтобы прибегнуть к насилию для изменения статус-кво, а этот риск Украина не может себе позволить [16]. Меры должны включать предоставление местным выборным советам в каждой области полномочия выбирать своих губернаторов. Это поможет гарантировать, что местное правительство сможет заслужить доверие и удовлетворить потребности своего населения, а не будет просто служить президенту и представлять национальное большинство. Кроме того, эта структура может служить в качестве важного плацдарма для местных по- 
литиков, где они смогут продемонстрировать свои лидерские способности и стать конкурентоспособными кандидатами на более высокие посты [15].

Президент Порошенко движется в правильном направлении, когда заявляет, что власти готовы начать процесс децентрализации. Тем не менее, важность такого шага необходимо подчеркнуть за пределами правящей партии, а реализация зависит от более широкого парламента, который подавляющим большинством проголосует за изменение конституции [14].

\section{б. Разрешение крымского кризиса}

Даже сейчас, когда внимание направлено на прекращение насилия в Восточной Украине, крымская ситуация не должна игнорироваться ни при каких обстоятельствах. Западные деятели не могут принять односторонний референдум о выходе из Украины, справедливость которого критики ставят под вопрос, или аннексию Россией региона, так как это нарушает нормы международного права, а также конституции Крыма и Украины.

Сейчас, когда российский рубль и российские законы на территории Крыма уже введены в действие, Запад должен решить стратегически, как иметь дело с полуостровом. Продолжение неэффективной войны санкций или военное вмешательство лишь усугубит ситуацию. Вместо этого, как часть процесса урегулирования, Украина и Россия могут назначить общенациональный референдум, в котором всем украинцам будет предоставлено право голоса относительно будущего статуса Крыма, с условием, что голоса крымского населения будут иметь больший вес. Это отменит одностороннюю и сомнительную с точки зрения свободы выборов природу предыдущего референдума и сделает его демократическим инклюзивным процессом, соответствующим международным и национальным законам. Если таким образом Крым вернется в Украину, он сможет продолжать быть автономией, полученной до настоящего времени, или пересмотреть ее, но так чтобы его собственная конституция была подчинена конституции Украины по вопросам юрисдикции [17]. Если Крым присоединяется к России, украинцам и другим меньшинствам, таким как татары, которые боятся преследования [18], должен быть предоставлен выбор, остаться с полными правами или мирно уйти [19].

в. Поддержание экономической безопасности как путь к политической безопасности

Не следует упускать из виду экономические факторы, которые сопутствуют политическим трудностям как существенные мотивы конфликта. Среднестатистический украинец на 20\% беднее сейчас, чем был до падения бывшего Советского Союза'. Сочетание мрачных перспектив заработка и низкой стоимости ассоциированного с конфоликтом капитала, предоставленного Россией сепаратистам, такого как военное вооружение и организационные навыки, позволили напряжению проявить себя через насилие. Для борьбы с этим Киев должен рассмотреть вопрос о предоставлении позитивных стимулов для сепаратистов, способствующих прекращению боевых действий, таких как рассмотрение возможностей выкупа оружия (в виде денежных средств или других товаров и услуг) как в краткосрочной, так и долгосрочной перспективе.

Кроме того, Западом в значительной степени игнорируются негативные последствия удержания Киевом 2,6 млрд долларов пенсионных выплат и платежей государственным служащим (например, работникам

$1 \mathrm{http}: / /$ www.themarker.com/wallstreet/1.2497610 школ и больниц) для местного населения в районах, контролируемых сепаратистами [20]. Киев должен рассмотреть прекращение карательных мер, которые ухудшают и без того ужасные условия для местного населения, и лишний раз доказывают, что Запад игнорирует народ и способствует дальнейшей маргинализации местных жителей, толкая их к пророссийским силам [2].

Также, вместо того чтобы поощрять рост Украины, Запад наложил суровые меры жесткой экономии. Учитывая серьезность событий в Украине и их потенциальных международных последствий, стоит переоценить эффективность такой политики и рассмотреть пути оказания фринансовой и технической помощи Украине для обеспечения стабильности в краткосрочной и долгосрочной перспективе.

г. Заключение верных альянсов: Евросоюзу - да, НАTO - нет

В эти непростые времена очень важно, чтобы Украина и международное сообщество стратегически подошли к тем партнерским отношениям, которые позволят стране добиться устойчивого мира. В связи с этим Украине должна быть предоставлена возможность вступить в Европейский Союз, но не в НАТО, где ее статус может быть пересмотрен через несколько десятилетий, чтобы обеспечить стабильность в регионе.

Интеграция Украины в ЕС пользуется беспрецедентной поддержкой общественности, как стало ясно в 2013 г. в ходе протестов на киевской центральной площади Майдан [21] и последующего подписания Соглашения об ассоциации [там же]. Для этого Европейская комиссия взяла на себя обязательство осуществить ряд экономических и фринансовых мер для поддержки реформ, необходимых для стабилизации ситуации в стране и обеспечения интеграции [там же].

Шаги на пути к членству в ЕС должны продолжаться при условии, что интеграция принесет возможности для устойчивого экономического развития и процветания в регионе. Однако для России и ее соседей необходимо прояснить, что наличие тесных связей с Европой не будет означать поворота к той или иной сфере влияния, не противоречит и не наносит ущерб поддержанию тесных связей и торговли с Евразией.

С другой стороны, Украине нельзя позволить вступить в НАTO, хотя эта возможность может быть пересмотрена лет через 20. Все в таком роде будет представлять собой серьезную угрозу для безопасности в регионе.

Хотя официальные лица признают, что их страна далека от удовлетворения требований НАТО, декабрьский законопроект о снятии внеблокового статуса страны и движение в направление соответствия критериям членства означает, что Украина будет подавать заявку, если сочтет, что одобрение вероятно.

Законопроект вызвал недовольство Москвы, которая видит в НАТО одного из важнейших соперников за влияние в регионе [6]. Не удивительно, что премьерминистр России Дмитрий Медведев предупредил, что принятие закона "превратит Украину в возможного военного противника для России" [22]. Таким образом, рационально было бы поддерживать ненасильственные решения по преодолению кризиса, НАТО должна отказаться от такой возможности.

Кроме того, западное военное вмешательство, скорее всего усилит представление о конфрликте как международной войне, а не украинской гражданской войне, каковая формулировка скорее приведет Россию к соглашению. Главным приоритетом в настоящий мо- 
мент должно быть прекращение насилия, а привлечения Киева в НАТО приведет лишь к обострению конфликта [там же].

\section{Заключение}

Немедленное принятие намеченных шагов по урегулированию конфликта и долгосрочное применение методов трансформации конфликта может позволить Украине вырасти в благополучную и мирную нацию. Однако в этом процессе Украина не может позволить себе быть пешкой в опосредованной войне Востока и Запада. Напротив, ей нужно занять активную позицию, одновременно признавая свое стратегическое положение, дающее свой потенциал, но и тот фракт, что сейчас она может позволить себе пойти на компромисс по таким вопросам, как Крым и НАТО, учитывая необходимость регионального сотрудничества по глобальным вызовам, и учитывая, что в ближайшие годы во властных отношениях, вероятно, произойдут огромные изменения.

\section{ЛИТЕРАТУРА}

1. Ukraine crisis: Army retreats at Donetsk airport [Электронный ресурс]. - Режим доступа : http://www.bbc.com/news/ world-europe-30929344.

2. Driving Ukrainians Into Putin's Arms [Электронный ресурс]. - Режим доступа : http://www.nytimes.com/2014/12/09/opinion/ driving-ukrainians-into-putins-arms.html? $r=0$.

3. Crafting a win-win-win for Russia, Ukraine and the West [Электронный ресурс]. - Режим доступа : http://www. washingtonpost.com/opinions/crafting-a-win-win-win-for-russiaukraine-and-the-West/2014/12/05/727d6c92-7be1-11e4-9a276fdbc612bff8_story.html.

4. Kissinger $\mathrm{H}$. To settle the Ukraine crisis, start at the end [Электронный ресурс] / H. Kissinger. - Режим доступа : http:// www.washingtonpost.com/opinions/henry-kissinger-to-settlethe-ukraine-crisis-start-at-the-end/2014/03/05/46dad868-a49611e3-8466-d34c451760b9_story.html.

5. At the heart of the Ukraine conflict is a conflict about what actually happened [Электронный ресурс]. - Режим доступа : http://qz.com/213318/at-the-heart-of-the-ukraine-conflict-is-aconflict-about-what-actually-happened/.

6. Fisher Sabine. Escalation in Ukraine: Conflicting Interpretation Hamper International Diplomacy [Электронный ресурс] / Fisher Sabine. - Режим доступа : http://www.swp-berlin.org/fileadmin/ contents/products/comments/2014C17 fhs.pdf.

7. President Putin's Fiction: 10 False Claims About Ukraine [Электронный ресурс]. - Режим доступа : http://www.state.gov/ r/pa/prs/ps/2014/03/222988.htm.

8. Lederach J. P. Conflict Transformation [Электронный ресурс] / J. P. Lederach. - Режим доступа : http://www.beyon dintractability.org/essay/transformation.
9. Dougherty J. Everyone Lies: The Ukraine Conflict and Russia's Media Transformation [Электронный ресурс] / J. Dougherty. - Режим доступа : http://shorensteincenter.org/ wp-content/uploads/2014/07/d88-dougherty.pdf.

10. OSCE in Ukraine: "Facts as basis for politics" [Электронный ресурс]. - Режим доступа : http://www.dw.de/osce-inukraine-facts-as-basis-for-politics/a-17551906.

11. OSCE Special Monitoring Mission to Ukraine [Электронный ресурс]. - Режим доступа : http://www.osce.org/ukrainesmm.

12. UKRAINE: Dialogue and East-West cooperation are the key [Электронный ресурс]. - Режим доступа : http:// worldbeyondwar.org/ukraine-dialogue-east-West-cooperationkey/.

13. Ukraine, Not Ready for Divorce [Электронный ресурс]. Режим доступа : http://www.nytimes.com/2014/03/06/opinion/ ukraine-not-ready-for-divorce.html.

14. Would a federal Ukraine be viable? [Электронный peсурс]. - Режим доступа : http://www.dw.de/would-a-federalukraine-be-viable/a-17404541.

15. Myerson R. A Call for Political Decentralization in Ukraine [Электронный ресурс] / R. Myerson. - Режим доступа : http:// www. huffingtonpost.com/roger-myerson/a-call-for-politicaldece b 4903795.html.

16. Germany urges Ukraine ti accept federal solution with separatists [Электронный ресурс]. - Режим доступа : http:// www.ft .com/cms/s/0/2 b 0 b 4 40c-2ac 8-11 e 4-811d00144feabdc0.html\#axzz3P Yc4pwa5.

17. Crimea Vote Deepens Crisis and Draws Denunciations [Электронный ресурс]. - Режим доступа : http:// www.nytimes.com/2014/03/07/world/europe/ukraine.html.

18. Vladimir Putin tells Crimea's Tatars their future lies with Russia [Электронный ресурс]. - Режим доступа : http:// www.theguardian.com/world/2014/may/16/vladimir-putin-crimeatatars-russian-ukraine.

19. Galtung J. Ukraine-Crimea - The Solution Is a Federation with High Autonomy [Электронный ресурс] / J. Galtung. - Режим доступа : http://www.ipsnews.net/2014/04/ukraine-crimeasolution-federation-high-autonomy/.

20. Kramernov A. E. (2014), Ukraine to Freeze Payments in Separatist Areas [Электронный ресурс] / A. E. Kramernov. Режим доступа : http://www.nytimes.com/2014/11/06/world/ europe/ukraine-to-freeze-payments-in-separatist-areas.html.

21. FACT SHEET "EU-Ukraine relations", Brussels, 17 February 2015, 150217/02 [Электронный ресурс]. - Режим доступа : http://www.eeas.europa.eu/statements/docs/2014/140514_ 02 en.pdf.

22. Bandow D. Ukraine Wants To Join NATO And Fight Russia: U.S. Must Say No And Make Alliance An Issue of Security, Not Charity [Электронный ресурс] / D. Bandow. - Режим доступа : http://www.forbes.com/sites/dougbandow/2014/12/26/ukrainewants-to-join-nato-and-fight-russia-u-s-must-say-no-and-makealliance-an-issue-of-security-not-charity/.

Бейлін Йосі,

Ph.D., директор організаиії Beilink, Business Foreign Affairs, екс-міністр юстицї̈ Ізраӥлю

Кравчук Ліат,

директор організачії Jeneba Project, Inc., Ізраїль

\section{ПОБУДОВА ДОРОЖНЬОЇ КАРТИ ДЛЯ ВИРІШЕННЯ КОНФЛІКТУ Й ПРОВЕДЕННЯ ПЕРЕТВОРЕНЬ В УКРАЇНІ}

У статті обґрунтовується підхід до трансформації українського конфлікту, в рамках якого нинішня криза визнається як прояв глибинних напруг. Пропонується двохаспектний підхід до досягнення миру в регіоні: а) шляхом здійснення багатосторонньої дипломатії, орієнтованої на зміну аспектів поведінки і установок учасників конфлікту; б) шляхом створення органу відновного правосуддя по типу південноафриканського комітету правди та примирення. Автор пропонує стратегічні кроки, спрямовані на мирне завершення конфллікту: 
а) проведення реформ з децентралізації України; б) вирішення питання Криму шляхом всенародного референдуму; в) позначення економічної безпеки як пріоритетного шляху для досягнення політичної безпеки; г) поступове створення стратегічних альянсів, які передбачать членство України в ЄС, але не в НАТО, в найближчі роки.

Ключові слова: Україна; Крим; конфолікт; дорожня карта; стратегія.

Beilin Yossi,

Ph.D., Director of Beilink, Business Foreign Affairs, former Israeli Justice Minister

Kravchuk Liat,

Director of Jeneba Project, Inc., Israel

\section{PAVING A ROADM AP TO CONFLICT RESOLUTION AND TRANSFORM ATION IN UKRAINE}

The article explains the approach to the transformation of Eastern Ukrainian conflict, in which the current crisis is recognized as a manifestation of deep-seated tensions. Features a two-pronged approach to achieving peace in the region: a) through the implementation of multilateral diplomacy, focused on changing aspects of the behaviour and attitudes of the parties to the conflict; b) by creating a body of restorative justice on the type of the South African Committee of truth and reconciliation. Suggested by the author strategic steps towards a peaceful end of the conflict, are: a) carrying out the decentralization reforms of Ukraine; b) the issue of Crimea by a national referendum; $C$ ) the designation of economic security as a priority the way to achieve political security; and (d) the gradual establishment of strategic alliances that will provide for Ukraine's membership in the EU but not NATO in the coming years. In his proposals author uses a large experience in this kind of problems on the conflicts on Middle East, Africa and Southern America areas.

Keywords: Ukraine; Crimea; conflict; roadmap; strategy.

\section{REFERENCES}

1. Ukraine crisis: Army retreats at Donetsk airport, available at: http://www.bbc.com/news/world-europe-30929344

2. Driving Ukrainians Into Putin's Arms, available at: http://www.nytimes.com/2014/12/09/opinion/driving-ukrainians-into-putinsarms.html? $r=0$

3. Crafting a win-win-win for Russia, Ukraine and the West, available at: http://www.washingtonpost.com/opinions/crafting-a-winwin-win-for-russia-ukraine-and-the-West/2014/12/05/727d6c92-7be1-11e4-9a27-6fdbc612bff8_story.html

4. Henry Kissinger (2014), To settle the Ukraine crisis, start at the end, available at: http://www.washingtonpost.com/opinions/ henry-kissinger-to-settle-the-ukraine-crisis-start-at-the-end/2014/03/05/46dad868-a496-11e3-8466-d34c451760b9 story.html

5. At the heart of the Ukraine conflict is a conflict about what actually happened, available at: http://qz.com/213318/at-the-heart-ofthe-ukraine-conflict-is-a-conflict-about-what-actually-happened/

6. Fisher Sabine (2014), Escalation in Ukraine: Conflicting Interpretation Hamper International Diplomacy, available at: http://www.swpberlin.org/fileadmin/contents/products/comments/2014C17 fhs.pdf

7. President Putin's Fiction: 10 False Claims About Ukraine, available at: http://www.state.gov/r/pa/prs/ps/2014/03/222988.htm

8. Lederach John Paul (2003), Conflict Transformation, available at: http://www.beyondintractability.org/essay/transformation

9. Dougherty Jill (2014), Everyone Lies: The Ukraine Conflict and Russia's Media Transformation, available at: http:// shorensteincenter.org/wp-content/uploads/2014/07/d88-dougherty.pdf

10. OSCE in Ukraine: "Facts as basis for politics", available at: http://www.dw.de/osce-in-ukraine-facts-as-basis-for-politics/a17551906

11. OSCE Special Monitoring Mission to Ukraine, available at: http://www.osce.org/ukraine-smm

12. UKRAINE : Dialogue and East-West cooperation are the key, available at: http://worldbeyondwar.org/ukraine-dialogue-eastWest-cooperation-key/

13. Ukraine, Not Ready for Divorce, available at: http://www.nytimes.com/2014/03/06/opinion/ukraine-not-ready-for-divorce.html

14. Would a federal Ukraine be viable?, available at: http://www.dw.de/would-a-federal-ukraine-be-viable/a- 17404541

15. Myerson Roger (2014), A Call for Political Decentralization in Ukraine, available at: http://www.huffingtonpost.com/rogermyerson/a-call-for-political-dece_b_4903795.html

16. Germany urges Ukraine ti accept federal solution with separatists, available at: http://www.ft.com/cms/s/0/2b0b440c-2ac811e4-811d-00144feabdc0.html\#axzz3P Yc4pwa5

17. Crimea Vote Deepens Crisis and Draws Denunciations, available at: http://www.nytimes.com/2014/03/07/world/europe/ ukraine.html

18. Vladimir Putin tells Crimea's Tatars their future lies with Russia, available at: http://www.theguardian.com/world/2014/may/16/ vladimir-putin-crimea-tatars-russian-ukraine

19. Galtung Johan (2014), Ukraine-Crimea - The Solution Is a Federation with High Autonomy, available at: http://www.ipsnews.net/ 2014/04/ukraine-crimea-solution-federation-high-autonomy/

20. Kramernov Andrew E. (2014), Ukraine to Freeze Payments in Separatist Areas, available at: http://www.nytimes.com/2014/11/ 06/world/europe/ukraine-to-freeze-payments-in-separatist-areas.html

21. FACT SHEET "EU-Ukraine relations", Brussels, 17 February 2015, 150217/02, available at: http://www.eeas.europa.eu/statements/ docs/2014/140514 02 en.pdf

22. Bandow Dug (2014), Ukraine Wants To Join NATO And Fight Russia: U.S. Must Say No And Make Alliance An Issue of Security, Not Charity, available at: http://www.forbes.com/sites/dougbandow/2014/12/26/ukraine-wants-to-join-nato-and-fight-russia-u-s-mustsay-no-and-make-alliance-an-issue-of-security-not-charity/

(C) Бейлин Йоси, Кравчук Лиат

Надійшла до редакції 23.01.2015

№ 2 (134), спецвипуск, лютий 2015 р. 